\title{
Factors affecting the incidence of chronic lung disease of prematurity in 1987, 1992, and 1997
}

\author{
B N Manktelow, E S Draper, S Annamalai, D Field
}

\begin{abstract}
Objective-To determine changes in the incidence of chronic lung disease of prematurity between 1987, 1992, and 1997. Methods-Observational study based on data derived from a geographically defined population: Trent Health Region, United Kingdom. Three time periods were compared: 1 February 1987 to 31 January 1988 (referred to as 1987); 1 April 1992 to 31 March 1993 (referred to as 1992); 1997. All infants of $\leqslant 32$ completed weeks gestation born to Trent resident mothers within the study periods and admitted to a neonatal unit were included. Rates of chronic lung disease were determined using two definitions: (a) infants who remained dependent on active respiratory support or increased oxygen at 28 days of age; (b) infants who remained dependent on active respiratory support or increased oxygen at a corrected age of 36 weeks gestation.
\end{abstract}

Results-Between 1987 and 1992 there was a fall in the birth rate, but a significant increase was noted in the number of babies of $\leqslant 32$ weeks gestation admitted to a neonatal unit. There was no significant change in survival when the two groups of infants were directly compared. However, mean gestation and birth weight fell. Adjusting for this change showed a significant improvement in survival ( 28 day survival: odds ratio $(O R)=1.69 ; 95 \%$ confidence interval $(95 \% \mathrm{CI})=1.23$ to 2.33 . Survival to 36 week corrected gestation: $\mathrm{OR}=1.45 ; 95 \% \mathrm{CI}=1.06$ to 1.98$)$. These changes were accompanied by a large increase in the incidence of chronic lung disease even after allowing for the change in population characteristics ( 28 day definition: $\mathrm{OR}=2.20 ; 95 \% \mathrm{CI}=1.47$ to 3.30 . 36 week definition: $O R=3.04 ; 95 \%$ CI $=1.91$ to 4.83 ). Between 1992 and 1997 a different pattern emerged. There was a further increase in the number of babies admitted for neonatal care at $\leqslant 32$ weeks gestation despite a continuing fall in overall birth rate. Survival, using both raw data and data corrected for changes in gestation and birth weight, improved significantly in 1997 (adjusted data: 28 day survival: $\quad O R=1.72(95 \% \quad C I=1.22$ to 2.38); survival to 36 week corrected gestation: $\mathrm{OR}=1.90(95 \% \mathrm{CI}=1.36$ to 2.64$))$. Rates of chronic lung disease showed no significant change between 1992 and 1997 despite improved survival (adjusted data: 28 day definition: $O R=0.72 \quad(95 \%$
$\mathrm{CI}=\mathbf{0 . 5 0}$ to 1.03$) ; 36$ week definition: OR $=0.88(95 \% \mathrm{CI}=0.61$ to 1.26$)$.

Conclusions-Current high rates of chronic lung disease are the result of policies to offer neonatal intensive care more widely to the most immature infants. Recent improvements in survival have been achieved without further increases in the risk of infants developing chronic lung disease.

(Arch Dis Child Fetal Neonatal Ed 2001;85:F33-F35)

Keywords: prematurity; chronic lung disease; respiratory disease; incidence

In the 30 years since bronchopulmonary dysplasia was first described in preterm infants, ${ }^{1}$ a huge medical literature has evolved on the topic and its implications. There is no doubt that chronic lung disease (CLD) remains a major problem in neonatal units. Reported estimates of incidence and time trends have shown great variation, but many of these studies have been based on hospital populations that are not ideal for such work because of the potential for referral bias. ${ }^{2-6}$

Even the most widely tested developments in care have been difficult to assess in terms of their impact on the incidence of CLD. Randomised trials were generally focused (and hence sized) on acute outcomes such as death. Subsequent meta analyses have provided insight into the effect of surfactant and antenatal steroids on CLD. ${ }^{7-11}$ Many other treatments have been introduced into neonatal intensive care-for example, oscillatory ventilation, trigger ventilation, postnatal steroids, nitric oxide, increased use of constant positive airway pressure (CPAP) - with much less careful assessment. The overall effect of these, even on survival, is not clear.

Given the major innovations that have taken place in perinatal care in recent years, we wished to investigate the extent to which the incidence of the condition had changed using a large geographically defined population.

\section{Methods}

The Trent Neonatal Survey (TNS) is a continuing study of neonatal intensive care activity in the Trent Health Region (United Kingdom) and has been described previously. ${ }^{12}$

Trent has a population of roughly 4.6 million and there are about 60000 births per year. The region is recognised as being representative of England and Wales as a whole.

Three time periods spanning 10 years were chosen to investigate changes in the incidence of CLD: 
Table 1 Survival of infants of $\leqslant 32$ weeks gestation, admitted for neonatal care, at 28 days of age and 36 weeks corrected gestation

\begin{tabular}{llllll}
\hline Year & $\begin{array}{l}\text { No of infants } \\
\text { admitted for NIC }\end{array}$ & $\begin{array}{l}\text { No of survivors } \\
\text { at 28 days (\%) }\end{array}$ & $\begin{array}{l}\text { No of survivors at 36 weeks } \\
\text { corrected gestation (\%) }\end{array}$ & $\begin{array}{l}\text { Survival to 28 days adjusted for } \\
\text { birth weight and gestation OR } \\
\text { (95\% CI) }\end{array}$ \\
\hline 1987 & 802 & $664(83)$ & $663(83)$ & $1987: 1992$ & $1.69(1.23$ to 2.33) \\
1992 & 856 & $725(85)$ & $710(83)$ & $1992: 1997$ & $1.72(1.22$ to 2.38) \\
1997 & 934 & $833(89)$ & $826(88)$ & 1.38 weight and gestation OR (95\% CI)
\end{tabular}

Odds ratios for survival (at 28 days of age and 36 weeks corrected gestation) comparing 1987 with 1992 and 1992 with 1997, adjusted for changes in birth weight and gestational age, are also shown.

NIC, Neonatal intensive care.

- 1 February 1987 to 31 January 1988, the earliest data available from the TNS. For descriptive purposes we termed this period 1987.

- 1 April 1992 to 31 March 1993. An expansion of the dataset on 1 April 1992 made this period more suitable than the calendar year 1992. Nonetheless for descriptive purposes we termed this period 1992.

- 1997. The whole year of 1997 was used.

We used both of the common definitions of $\mathrm{CLD}^{2}{ }^{13}$ :

- infants who remain dependent on active respiratory support or increased oxygen at 28 days of age;

- infants who remain dependent on active respiratory support or increased oxygen at a corrected age of 36 weeks gestation.

STATISTICAL ANALYSIS

Distribution free analysis of variance (KruskalWallis test ) was used to compare median gestation and Apgar scores over the three reported years. Changes in birth weight adjusted for study year and gestation were investigated using a weighted least squares regression model. The odds ratios (OR) for survival and CLD were estimated using logistic regression modelling. Other variables were compared using a $\chi^{2}$ test, or a $\chi^{2}$ test for trend where appropriate. SAS v6.12 was used for all analyses.

\section{Results}

During the 10 years spanned by the study, the total number of births in the region fell from 61050 to 55780 per year. However, this change was accompanied by a significant increase $(p<0.001)$ in the number of infants of $\leqslant 32$ completed weeks gestation admitted to a neonatal unit (802 to 934). Similarly median gestation fell by one week $\left(\chi^{2}(\mathrm{df}=2)=12.9\right.$; $\mathrm{p}=0.0016)$. Closer examination (MannWhitney test) suggested that there was a significant difference between 1987 and 1992 $(\mathrm{p}=0.0018)$, but not 1992 and 1997 $(p=0.96)$. After differences in gestation were taken into account, there was evidence of a reduction in mean birth weight across the three time periods $(\mathrm{p}=0.027)$. Comparison of 1987 with 1992 showed a fall of $13 \mathrm{~g}$, with a fall of 17 g between 1992 and 1997.

No change in median Apgar score was noted between the years, and male to female ratio was similarly constant, with about $57 \%$ of infants being male in each year. Not surprisingly, both antenatal steroid and surfactant use increased significantly during the period $(p<0.001$ for both; surfactant was not commercially available in 1987 and antenatal steroid use was not established practice). There was also an increase in the proportion of babies born by caesarean section $(p<0.001)$ but not in the proportion requiring ventilation $(\mathrm{p}=0.85)$.

When survival at 28 days in 1987 was compared directly with that in 1992, no significant difference was seen $\quad(O R=1.15 ; 95 \%$ $\mathrm{CI}=0.88$ to 1.49 ). However, comparing 1992 with 1997 showed a significant improvement $(\mathrm{OR}=1.49 ; 95 \% \mathrm{CI}=1.13$ to 1.97$)$. The same pattern was seen with survival to 36 weeks $(1987 \quad v$ 1992: $\quad$ OR $=1.02 \quad(95 \%$ $\mathrm{CI}=0.79$ to 1.32$) ; 1992 v 1997: \mathrm{OR}=1.57$ $(95 \% \mathrm{CI}=1.20$ to 2.06$)$. Table 1 shows data on survival at 28 days of age and 36 weeks corrected gestation, adjusted for the changes in birth weight and gestation described above. Correcting for the change in birth weight and gestation of the population showed a significant improvement in the odds ratio for survival for both time comparisons and age cut offs.

Table 2 shows the rates of CLD in the three time periods with the relevant comparisons. The data by both definitions show the same pattern. Improved survival between 1987 and 1992 resulted in a large increase in CLD. Improved survival between 1992 and $1997 \mathrm{did}$ not produce a similar change. The data from the latter comparison show a trend suggesting that the risk of developing CLD was decreased, but this did not reach statistical significance. However, in 1997 an increasing proportion of

Table 2 Rates of chronic lung disease (CLD), using the 28 day and 36 week definitions

\begin{tabular}{|c|c|c|c|c|c|}
\hline Year & $\begin{array}{l}\text { No of survivors who received } \\
\text { ventilation (\%) }\end{array}$ & No with CLD (\%) & Comparison period & $\begin{array}{l}\text { Odds ratio } \\
(95 \% \text { CI) for } C L D\end{array}$ & $\begin{array}{l}\text { Odds ratio }(95 \% \text { CI) for CLD adjusted } \\
\text { for birth weight and gestational age }\end{array}$ \\
\hline \multicolumn{6}{|c|}{28 day definition } \\
\hline 1987 & $305(46)$ & $75(25)$ & & & \\
\hline 1992 & $365(50)$ & $148(41)$ & $1987: 1992$ & 2.09 (1.50 to 2.92$)$ & $2.20(1.47$ to 3.30$)$ \\
\hline 1997 & $388(47)$ & $162(42)$ & $1992: 1997$ & $1.05(0.72$ to 1.40$)$ & $0.72(0.5$ to 1.03$)$ \\
\hline \multicolumn{6}{|c|}{36 week definition } \\
\hline 1987 & $304(46)$ & $33(11)$ & & & \\
\hline 1992 & $350(49)$ & $92(26)$ & $1987: 1992$ & $2.93(1.90$ to 4.51$)$ & $3.04(1.91$ to 4.83$)$ \\
\hline 1997 & $382(46)$ & $110(29)$ & $1992: 1997$ & $1.13(0.82$ to 1.57$)$ & $0.88(0.61$ to 1.26$)$ \\
\hline
\end{tabular}

Odds ratios for CLD comparing 1987 with 1992 and 1992 with 1997, both adjusted and unadjusted for changes in birth weight and gestational age, are also shown. 
infants received constant positive airway pressure (CPAP) alone as their active respiratory support. If these infants are included with the ventilated group who survived 28 days, the odds ratio for CLD (28 day definition) shows a statistically significant fall between 1992 and 1997 (1992, $\mathrm{n}=366 ; 1997, \mathrm{n}=459$; OR for CLD adjusted for birth weight and gestation 0.63 (95\% CI 0.44 to 0.89$)$ ).

\section{Discussion}

During the last decade there has been a good deal of speculation about whether, and to what extent, the incidence of CLD has changed. This study provides an insight into the nature of the changes that have occurred in Trent in recent years, and these are likely to have been paralleled in many developed countries.

Of fundamental importance appears to be the increased number of babies of $\leqslant 32$ weeks gestation being admitted to neonatal units during the study period. Although similar changes are likely to have occurred elsewhere, the time scale for such changes may well have varied, certainly between countries and perhaps even different regions of the same country. Variation of this type may well explain some of the apparent differences between what appear to be similar neonatal services. Without data to assess such variation in practice, it will remain difficult, if not impossible, to assess reliably performance over time or between individual units. ${ }^{4} 614$

In terms of CLD, the two time periods considered show quite different patterns. Between 1987 and 1992, as more infants of $\leqslant 32$ weeks gestation were admitted for intensive care, survival improved, but this was associated with a large rise in the number of babies who developed CLD (double by the 28 day definition, treble by the 36 week definition). In contrast, a somewhat greater improvement in survival between 1992 and 1997 was accompanied by no statistically significant change in the risk of CLD. The trend in the data for this second time period suggests that the risk of developing CLD may have fallen, but the change did not reach statistical significance. The improved outcome noted when infants treated with CPAP only were included in the comparison groups should be considered with caution because opinions on CPAP as an alternative, albeit unproven, to ventilation changed considerably between 1992 and $1997 . .^{15}$ Given the nature of the population, with care being given by 16 different hospitals, it is impossible to equate the better performance in relation to CLD during the second five year period to a particular strategy of care, such as permissive hypercapnia, ${ }^{2}$ or new intervention, such as oscillation, because only one or two institutions have joint protocols.

Currently there are a number of theories about the causes of CLD. These can be broadly divided into those that point to a major influence of in utero factors, particularly infection or inflammation, ${ }^{6}{ }^{17-19}$ and those relating to exposures after birth, ${ }^{620}$ especially the nature and extent of respiratory support. The data from this study were obtained at a time when various strategies were being used to improve the package of supportive care available to the preterm infant. No comparable measures were in place to try to alter the inflammatory exposure of the infant while in utero. It seems therefore that the changes observed reflect the interaction of ex utero care and the infants maturity, confirming the importance of interventions such as ventilation in the production of CLD. The influence of in utero events is likely to have been a constant factor during the study and, given the continuing health economic importance of CLD, probably offers the best opportunity for new research to make a genuine impact on the condition.

We wish to acknowledge the continuing help and collaboration of the hospitals delivering perinatal care in both Trent and adjacent regions. This study is one of the Trent Infant and Mortality and Morbidity Studies (TIMMS), which are funded by the
Trent Regional Health Service. E S D is supported by a grant from Leicestershire Health Authority.

1 Northway WH, Rosan RC, Porter DY. Pulmonary disease following respiratory therapy for hyaline membrane disease: bronchopulmonary dysplasia. $N$ Engl $\mathcal{f} \mathrm{Med}$ 1967;267:357-68.

2 Avery ME, Tooley WH, Keller JB, et al. Is chronic lung disease in low birth weight infants preventable? A survey of eight centers. Pediatrics 1987;79:26-30.

3 Fanaroff AA, Wright LL, Stevenson DK, et al. Very low birth weight outcomes of the National Institute of Child Health and Human Development Neonatal Research Network. May 1991 through December 1992. Am f Obstet work. May 1991 through Ded
Gynecol 1995;173:1423-31.

4 Hack M, Fanaroff AA. Outcomes of children of extremely low birthweight and gestational age in the 1990s. Early Hum Dev 1999;53:193-218.

5 Beeby P, Chan D, Henderson-Smart D. Improved outcomes following the introduction of surfactant to an Australian neonatal unit. $\mathcal{F}$ Pediatr Child Health 1996;32:257-60

6 Todd DA, Jana A, John E. Chronic oxygen dependency in infants born at 24-32 weeks' gestation: the role of antenatal and neonatal factors. $\mathcal{F}$ Pediatr Child Health 1997;33:402-7.

7 Crowley PA. Antenatal corticosteroid therapy: a metanalysis of the randomised trials, 1972 to 1994. Am F Obstet Gynecol 1995;173:254-62.

8 NIH Consensus Development Panel on the Effects of Corticosteroids for Fetal Maturation on Perinatal Outcomes. Effect of corticosteroids for fetal maturation on perinatal outcomes. FAMA 1995;273:413-18

9 Soll RF. Prophylactic natural surfactant extract for preventing morbidity and mortality in preterm infants (Cochrane Review). In: The Cochrane Library. Oxford: update software, Issue 1, 2000.

10 Soll RF. Prophylactic synthetic surfactant for preventing morbidity and mortality in preterm infants (Cochrane Review).In: The Cochrane Library. Oxford: update software, Issue 1,2000

11 Soll RF. Synthetic surfactant for respiratory distress syndrome in preterm infants (Cochrane Review).In: The

12 Field D, Draper ES. Survival and place of delivery 1994-96. Arch Dis Child 1999;80:F111-14.

13 Shennan AT, Dunn MS, Ohlsson A, et al. Abnormal pulmonary outcomes in premature infants: prediction from oxygen requirement in the neonatal period. Pediatrics 1988;82:527-32.

14 Young TE, Kruyer LS, Marshall DD, et al. Populationbased study of chronic lung disease in very low birth weight infants in North Carolina in 1994 with comparisons with 1984. Pediatrics 1999;104:17.

15 Jacobsen T, Gronvall J, Petersen S, et al. Minitouch treatment of very low birthweight infants. Acta Paediatr Scand 1993;82:934-8.

16 Kamper J, Wulff K, Larsen C, et al. Early treatment with nasal continuous positive airway pressure in very low nasal continuous positive airway pressure in very low
birthweight infants. Acta Paediatr Scand 1993;82:193-7.

17 Cassell GH, Waites KB, Crouse DT, et al. Association of Ureaplasma urealyticum infection of the lower respiratory tract with chronic lung disease and death in very-lowbirth-weight infants. Lancet 1988;2:240-5

18 Yoon BH, Romero R, Kim KS, et al. A systemic fetal inflammatory response and the development of bronchopulmonary dysplasia. Am f Obstet Gynecol 1999;181:773-9.

19 Yoon BH, Romero R, Jun JK, et al. Amniotic fluid cytokines (interleukin-6, tumor necrosis factor-alpha, interleukin-1 beta, and interleukin-8) and the risk for the development of bronchopulmonary dysplasia. Am f Obstet Gynecol 1997;177:825-30.

20 Kraybill EN, Runyan DK, Bose CL, et al. Risk factors for chromic lung disease in infants with birth weights 751 to 1000 grams. F. Pediatr 1989;115:15-120. 